\title{
The impact of MILA market-maker facility on volatility of the Colombian stock market
}

\author{
Benedicto Kulwizira Lukanima ${ }^{1}$ \\ (D) https://orcid.org/0000-0002-4391-5679 \\ Email: blukanima@uninorte.edu.co \\ Yuli Paola Gómez-Bravo ${ }^{1}$ \\ (D) https://orcid.org/0000-0001-6851-3978 \\ Email:ygomez@uninorte.edu.co \\ Luis Javier Sanchez-Barrios ${ }^{1}$ \\ (D) https://orcid.org/0000-0001-5140-3860 \\ Email: Isanchez@uninorte.edu.co
}

${ }^{1}$ Universidad del Norte, Business School, Barranquilla, Atlantico, Colombia

Received on 05.07.2020 - Desk acceptance on 07.08.2020 - 2nd version approved on 11.27.2020

Editor-in-Chief: Fábio Frezatti

Associate Editor: Fernanda Finotti Cordeiro

\begin{abstract}
In 2014, the Colombian Stock Exchange commenced the implementation of its market-maker facility (MMF), aiming at improving market efficiency. This paper examines the impact of the MMF program on three volatility-related aspects: volatility persistence, risk premium, and information asymmetry. This paper provides new insights about the anticipated outcomes of Mercados Integrados Latinoamericanos (MILA) reforms, specifically the MMF on the volatility of the Colombian stock market. This topic has not been fully addressed in the existing literature. This study, therefore, provides useful information for regulators and policy makers, in endeavors to address key issues raised during the World Economic Forum (WEF) of 2016. This paper poses a challenge to policy makers and stock market regulators in Colombia to revisit the reform program and address the factors limiting the effectiveness of market reforms. This paper provides justification for replicating the study to cover other MILA countries due to existing differences in some domestic market policies and structures. The paper employs conditional variance models for measuring volatility persistence, risk premia, and information asymmetry. The models are employed on the COLCAP stock index (Colombia) observed from January 17, 2008 to May 30, 2019. Observations are divided into two samples - pre- and post-MMF. This paper provides evidence of the impacts of the MMF reforms in the Colombian stock market. Specifically, the MMF seems to have an impact on the following aspects: (i) the magnitude in which current returns depend on previous returns has increased; (ii) investment portfolio returns, which are generally low, have declined after the MMF, leading to less risk compensation; (iii) the MMF does not seem to have affected the volatility of market returns and information asymmetry; (iv) volatility persistence increased in magnitude.
\end{abstract}

Keywords: stock market reforms, MILA market-makers facility, volatility persistence, risk premium, information asymmetry.

Correspondence address

Benedicto Kulwizira Lukanima

Universidad del Norte, Business School

Km.5 Vía Puerto

Área Metropolitana - Barranquilla - Atlantico - Colombia 


\section{INTRODUCTION}

On March 6, 2014 the Colombian Stock Exchange joined the market-maker facility (MMF) and became the fourth stock market in Latin America to adopt this facility. This facility followed a novel market reform vehicle known as Mercados Integrados Latinoamericanos (MILA) network (that is, the Integrated Latin American Market, in Spanish), which was established in 2011 by three countries (Colombia, Chile, and Peru) and joined by Mexico in 2014. The main motive of MILA is to achieve market efficiency by creating and promoting cross border integration of stock markets in pacific alliance through the harmonization of regulations governing capital markets in the region, taking custody of involved participants in member countries, and promoting the use of advanced technology in stock markets. Operationally, MILA features a network of registered brokers in each of the four member countries, who are authorized to buy and sell stocks of any registered company listed on the integrated market in local currency. The MMF, therefore, intends to facilitate MILA integration by creating an effective communication network that enables a single issuance registration in any country to access investors in all four markets. More specifically, the MMF aimed at creating market efficiency by structuring and implementing a stockbroker's commitment to trade (buying and selling) stocks.

The literature documents a handful of studies on MILA, with few things in common. First, they suggest improved market integration following MILA. Second, they account for MILA performance in its early stages, without addressing subsequent developments, such as the MMF. Third, they do not provide sufficient evidence of specific circumstances of individual member countries regarding time-variant volatility. Whereas MILA comprises four member countries, this study focuses on Colombia due to several reasons. In June 2016, key issues were raised in the World Economic Forum (WEF), which highlighted key obstacles hindering the development of efficient capital markets in Colombia (Wyman, 2016). Based on performance indicators, during the WEF, recommendations were given on four key areas: encouraging greater issuer participation; improving the investor value proposition; enhancing market efficiency and transparency; and attracting global interest. The effects of MILA on the equity market in Colombia have been subject to diverse studies with no clear consensus.
Building on Yepes-Rios et al. (2015), their study on the Colombian stock market suggests early signs of improved internationalization by attracting international firms and changing the ownership and international status of some firms. As stated in Dorodnyk (2014), stock market integration should be associated with several benefits like improved competitiveness, transparency, information flow, cost efficiency, and accountability. Other studies on the Colombian market have indicated declining returns, but unchanged volatility following MILA (Lizarzaburu et al., 2015), low liquidity (García et al., 2015), as well as negative correlation with other member countries (Espinosa-Mendez et al., 2017). According to Sandoval et al. (2015), the Colombian market benefited from MILA as a result of a reduction in systematic risk. Hence, these effects should be reflected on stock price volatility due to improved market competition.

Moreover, Colombian Stock Exchange is one of growing emerging markets in Latin America. Its turnover ratio was among the lowest in emerging markets, with a low free float of less than $30 \%$ in 2016 that has reached $40 \%$ in 2019. It, therefore, makes sense to conduct a study on a growing emerging market in Latin America, such as Colombia, given its relevance not only at a regional level, but also globally. This study contributes to further understanding a market for which previous studies have either not covered or results are still inconclusive. Specifically, the study focuses on an aspect that has not been addressed previously from a comprehensive perspective - the impact of MMF on the volatility of the Colombian Stock Exchange within the MILA context.

Volatility is important in stock markets because it affects decision making among investors and policymakers. This study, therefore, examines three volatility-related aspects: volatility persistence, risk premium and information asymmetry. These phenomena are relevant in the context of Colombia's MMF reforms because MILA integration imply increased market size and competition. To the best of our knowledge, the literature has not documented the impact of MMF in respect of volatility in the Colombian market - most of the previous studies cover MILA before adaptation of MMF. If MILA and the MMF are effective, the impact should be reflected in volatility persistence, risk premium, and information asymmetry. Indeed, we pose a challenging question of whether the stock market responds to MILA and the MMF as a viral reform 
instrument. Answers to this question contribute to new knowledge that enlightens reform implications for investors, policymakers, and regulators.

Our empirical analysis uses the stock index (COLCAP) on time-variant volatility models to examine if MILA (post-MMF) has made any impact in the market. Our findings suggest the following. First, overall, high volatility persistence, information asymmetry, and risk compensation are evident in the Colombian stock market. Second, the MMF seems to have an impact on the following aspects: (i) the magnitude in which current returns depend on previous returns has increased substantially; (ii) investment portfolio returns, which are generally low, have declined after the MMF, leading to less risk compensation. Third, the MMF seems to have not affected the volatility of market returns and information asymmetry. We discuss these findings and their implications in relation to possible barriers that hinder market efficiency in Colombia as outlined during the WEF in 2016. Moreover, we call for policy makers and regulators to consider further measures to improve market efficiency.

The remainder of the paper is organized as follows: section 2 presents a critical literature review, while section 3 presents the methodology. Data and preliminary tests are described in section 4 , followed by empirical estimations in section 5. Results are discussed in section 6 , while a section 7 provides an overall conclusion.

\section{LITERATURE}

The existing literature has plenty of documented studies about the characteristics of emerging stock markets, including those in the MILA region. Among others, the most studied feature is related to market efficiency, in which emerging markets mainly exhibit inefficiency [e.g., Charles and Darné (2009) and Harrison and Moore (2012)], which is associated with thin trading, low liquidity, high transaction costs, and unreliable information. The efficiency phenomenon attracts researchers' interests because it tends to affect two major performance indicators in stock markets - returns and volatility. If markets are efficient, stock returns are expected to be volatile, but they should carry risk premium as a compensation for high volatility. Moreover, if markets are efficient, bad news and good news should have different impacts on volatility - bad news tends to trigger more volatility than good news. Therefore, the efficiency phenomenon has also been examined in conjunction with information asymmetry due to inequality in accessing information (Harris, 2003; Hasbrouck, 2007, 2009). The extent to which information is shared in stock markets depends on market characteristics and nature of its key players (Choi \& Sias, 2012; Choi et al., 2013; Chung \& Wang, 2016; Yang, 2003).

A handful of studies have investigated MILA under two major contexts: the regional context and individual countries' context. Overall, most of these studies concentrate on possible benefits of integration. Among studies in the regional context is Bolañosa et al. (2015), which focuses on the impact of MILA on profitability (return), risk, correlation, and market size. Overall, this study, which was conducted during the early stages of MILA, corroborates Lizarzaburu et al. (2015). Their findings suggest that MILA did not have an impact on both returns and volatility in the regional context. Nevertheless, there were signs of declining market size (trading volume). Leraul (2016) documents MILA plans, processes, and structure, in which the author suggests expected long-term gains among investors and issuers. These gains are mainly explained by expected lower transaction costs, reduced cross-border risks, and improved pricing mechanism and risk allocation.

Other studies on MILA have focused on market integration in respect of correlation and causal nexus. A study by Espinosa-Méndez et al. (2017) examines conditional correlation - their evidence of increased correlation is consistent with Bolañosa et al. (2015). Rojas-Mora and Chamorro-Futinico (2017) examine causal nexus among MILA countries. Their findings show declining return correlation, thereby contradicting earlier studies. However, long-term volatility transmission seemed to be increased following MILA. More importantly, the magnitude of intermarket shock responses is very low although the impacts decay quickly. Santillán-Salgado et al. (2017) combine both linear and non-linear models for correlation and integration. Their findings corroborate others by showing evidence of increased both linear correlation and causal relationship, but weakening nonlinear correlation. Sandoval et al. (2015), and later on Hardy et al. (2018), draw special attention by suggesting that actually MILA favored cointegration.

In relation to time-varying volatility, some studies on Latin American stock markets provide evidence of information asymmetry [e.g., Agudelo et al. (2011), Duarte and Young (2009), Martins and Paulo (2014), and Siqueira et al. (2017)]. Overall, these studies relate 
information asymmetry to liquidity, cost of equity, risk, normal returns, and company size. However, their results are contradicting about factors influencing information asymmetry across countries. Risk premium is a volatilityrelated phenomenon, which tends to be driven by several factors, both domestic and international. A study by Berggrun et al. (2016) examined MILA in the context of idiosyncratic risk. Their findings suggest that returns do not carry a risk premium for unsystematic risk, at least in the early stages of MILA.

Regarding Colombia, previous studies show conflicting results about the impact of MILA. According to Bolañosa et al. (2015), early signs of MILA showed slight improvements in stock returns, unchanged volatility and declining market size. Yepes-Rios et al. (2015) examine the post-MILA Colombian market, focusing on trading activities - ownership and internationalization of brokerage firms. They provide evidence of improvements in brokerage activities and changes in ownership structure among companies.

Previous studies have also addressed various aspects related with the Colombian stock market in the MILA context. According to Lizarzaburu et al. (2015), apart from showing declining profitability of integrated markets, the performance of the Colombian market indicated a slight positive trend after MILA. In terms of correlation among MILA countries, according to Espinosa-Mendez et al. (2017), Colombia shows a negative relationship. García et al. (2015) applied a Markowitz mean-variance model to the Colombian stock market between January 2005 and December 2014 - before the adoption of MMF. Their results show that the main problem faced by investors that implemented the portfolio theory was liquidity of stocks.

While most studies apply market level data, others have narrowed to firm and investors' level. Berggrun et al. (2016) take a different direction by applying firm level data. Their findings on Colombia firms show, on average, higher market capitalization and are more liquid than firms from Peru and Chile. Moreover, results obtained from the association between the standard deviation (SD) of Fama and French residuals and monthly returns show that such firms yielded greater median excess returns than those of peers. Sandoval et al. (2015) apply the conditional version of international CAPM and, through the measurement of markets cointegration before and after MILA, they found that Colombia, as a market, benefited from MILA as a result of a reduction in systematic risk. An anomaly of international CAPM was identified, with a significant effect in Colombia (and in the United States of America) before MILA, which disappeared after its implementation. Accordingly, Mellado and Escobari (2015) presented strong evidence of how MILA increased the levels of dynamic correlation between stock returns, with a decline in gains from international diversification by holding portfolios of diverse stocks of member countries.

To sum up, while the literature covers MILA, it falls short of subsequent reforms after MMF adaptation and it does not provide empirical evidence on the impact of the new developments on time-varying volatility. Hence, there is a necessity to uncover the knowledge gap about the impact of MMF in order to explain policy implications upon possible barriers to market performance. Colombia, which started implementing the MMF in 2014, shows disappointing evidence regarding transactions costs, liquidity, and returns. For the MMF to be meaningful, some improvements should be noticeable and reflected in the pricing mechanism, which covers volatility. We posit that, since the main objective of MMF is to facilitate MILA through enhancing effectiveness in stock trading, volatility should increase post-MMF and should be correctly priced in risk premium. Moreover, since MMF intends to improve information flow in the market, the magnitude of information asymmetry should increase.

From previous studies, volatility is a vital aspect in explaining the impact of MMF on each individual member country because the joint objective of the MMF (and MILA generally) is to improve market performance and internationalization. We should expect increased volatility due to external risk factors and cross-border volatility spillovers. Evidence of the relationship between market size and volatility is found in previous studies [e.g., Mukherjee and Mishra (2010), Todea (2016), and Zhang and Liu (2010)]. Arguably, volatility should not be considered harmful if it is consistent with economic fundamentals: that is, arising from absorption of new information about those fundamentals or expectations, which is reflected in stock pricing. Moreover, volatility persistence should be high - the realized volatility should have long memory in order to be consistent with stock market behaviors (Andersen et al., 2003). This phenomenon is usually related to lumpy information diffusion in stock markets (Bollerslev \& Jubinski, 1999; Chuang, 2015). A study by Dutta et al. (2017), on the Canadian stock market, shows that the adoption of an electronic trading system (similar to MMF) was associated with an increase in volatility persistence and negative information efficiency.

Moreover, we argue that, since the MILA reforms seem to be associated with changes in ownership structure as envisaged in Yepes-Rios et al. (2015), the effect should be reflected on risk premium and information asymmetry. Specifically, if volatility increases, we should expect an 
increase in risk premium [see Campbell (1992), French et al. (1987), Kumar (2018), Lintner (1965), Markowitz (1959), and Sharpe (1964)]. However, some studies on emerging markets show evidence of a negative relationship between volatility and risk premium, thereby contradicting the theory [e.g., Kumar (2018) and Sehgal and Garg (2016)]. Also, if MMF has improved market participation and information flow, we should expect the market investors' response to news to be consistent with empirical evidence - bad news to trigger more volatility than good news.
Hence, for the Colombian stock market, based on theory and empirical evidence from previous studies, we posit as follows:
$\mathrm{H}_{1}$ : the MMF is associated with an increase in volatility. If that is the case, an increase in volatility is associated with an increase in risk premium.
$\mathrm{H}_{2}$ : the MMF is associated with higher but not permanent volatility persistence.
$\mathrm{H}_{3}$ : the MMF is associated with an increase in the magnitude of information asymmetry.

\section{METHODOLOGY}

This study applies four different models, aiming at capturing conditional volatility, volatility persistence, information asymmetry, and risk premium. Since the original works by Engle (1982) and Bollerslev (1986), autoregressive conditional heteroskedasticity (ARCH) models have been transformed to become better workhorses in volatility modeling. A comprehensive review of the applications of these models is documented in the literature [e.g., Poon and Granger (2003) and Tripathy and Gil-Alana (2010)]. Overall, despite new developments in volatility modeling, the usefulness of ARCH-type models are notable as they continue to dominate stock market studies until recently [e.g., Guo and Neely (2008), Lee et al. (2001), Sanyal et al. (2016), Sharma and Vipul (2016), Srinivasan (2011), Tripathy and Gil-Alana (2015), and Zhou and Zhou (2005)]. In this paper, we apply a combination of three models, which are designated for examining information asymmetry: threshold GARCH (TARCH), exponential GARCH (EGARCH), and component GARCH (CGARCH).

The original GARCH (Bollerslev, 1986), with the mean and variance equations for $\operatorname{GARCH}(q, p)$ process can be written as:

$$
\begin{gathered}
R_{t}=\mu+\varepsilon_{t} ; \varepsilon_{t} / \Omega_{t-1} \simeq N\left(0, h_{t}\right) \\
h_{t}^{2}=\omega+\sum_{i=1}^{p} \alpha_{i} \varepsilon_{t-i}^{2}+\sum_{i=1}^{q} \beta_{i} h_{t-i}
\end{gathered}
$$

where $p$ and $q$ denote lag structures for ARCH and GARCH effects, respectively. In the mean equation (1), $R_{t}$ denotes the natural log of market stock returns, $\varepsilon_{t}$ is the error term, which is assumed to be normally distributed with 0 mean and variance $h_{t}$, and $\Omega_{\mathrm{t}-1}$ represents random information set available at time $t-1$. In the variance equation (2), the ARCH coefficient, $\alpha_{i}$, is a measure of the impact of news shocks on predicted conditional volatility, while the GARCH coefficient, $\beta$, measures the impact of past volatility. Jointly, $\alpha_{i}$ and $\beta_{i}$ measure volatility persistence. Thus, if the sum of $\alpha_{i}$ and $\beta_{i}$ is close to but less than 1 , it implies a persistent volatility effect of stock prices.

The TARCH (Glosten et al., 1993; Zakoïan, 1994), which has the capability to capture leverage effects, can be presented as follows:

$$
h_{t}^{2}=\omega+\sum_{i=1}^{p} \alpha_{i} \varepsilon_{t-i}^{2}+\sum_{i=1}^{p} \alpha_{i} S_{t-i} \varepsilon_{t-i}^{2}+\sum_{i=1}^{q} \beta_{i} h_{t-i}
$$

where

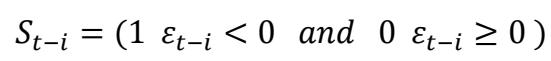

Thus, depending on whether $\varepsilon_{t-i}$ is above or below the threshold value of $0, \varepsilon_{t-i}^{2}$ has different effects on the conditional variance $h_{t}^{2}$ : such that when $\varepsilon_{t-i}$ is positive, the total effects are given by $\alpha_{i} \varepsilon_{t-i}^{2}$; when $\varepsilon_{t-i}$ is negative, the total effects are given by $\left(\alpha_{i}+\pi_{i}\right) \varepsilon_{t-i}^{2}$. Hence, $\pi_{i}$ should be positive for bad news to have larger impacts on conditional volatility.

In the EGARCH (Nelson, 1991), the effect of recent residuals is not quadratic like in the standard GARCH models. Its variance equation can be expressed as:

$$
\log \left(h_{t}^{2}\right)=\omega+\alpha\left|\frac{\varepsilon_{t-1}}{\sqrt{h_{t-1}^{2}}}\right|+\pi \frac{\varepsilon_{t-1}}{\sqrt{h_{t-1}^{2}}}+\beta \log \left(h_{t-1}^{2}\right)
$$

In equation 5, $\alpha$ explains the magnitude of conditional shocks on the conditional variance. Information asymmetry is captured by the coefficient $\pi$, in which good news and bad news have the same impact if $\pi=0$, a negative shock increases volatility more than a positive shock if $-1<\pi<0$, and positive shocks cause higher volatility than negative shocks if $\pi>0$. Volatility persistence is captured by the coefficient $\beta$. Recently, the 
same approach has been applied in stock market studies and seems to perform better than other models due to its nonlinearity feature [see Sharma and Vipul (2016), Srinivasan (2011), and Tripathy and Gil-Alana (2015)].

The CGARCH extension (Engle \& Lee, 1999) has the ability to describe the volatility dynamics better than other GARCH models because it can also distinguish the effects of the long-run and the short-run. To specify the model, the standard GARCH (1.1) model can be expressed in the following form:

$$
h_{t}^{2}=\omega^{\prime}+\alpha\left(\varepsilon_{t-1}^{2}-\omega^{\prime}\right)+\beta\left(h_{t-1}^{2}-\omega^{\prime}\right)
$$

Equation 6 shows mean reversion to $\omega^{\prime}$, which is constant over time: hence, ${ }^{h^{\prime 2}}=\frac{\omega}{1-\alpha_{1}-\beta_{1}}$ is the unconditional long-run level of volatility. To account for time-varying long-run volatility level, the components model allow mean reversion to a varying level $m_{t}$ as follows:

$$
\begin{gathered}
h_{t}^{2}-m_{t}=\alpha\left(\varepsilon_{t-1}^{2}-m_{t-1}\right)+\beta\left(h_{t-1}^{2}-m_{t-1}\right) \\
m_{t}=\omega+\rho\left(m_{t-1}-\omega\right)+\phi\left(\varepsilon_{t-1}^{2}-h_{t-1}^{2}\right)
\end{gathered}
$$

Equation 7 captures the transitory component, $h_{t}^{2}-m_{t}$, which converges to 0 with power of $(\alpha+\beta)$. In equation $8, m_{t}$ (which replaces $\omega$ ) is the component for long-run time-varying volatility, which converges to $\omega$ with power of $\rho$. Typically, $\rho$ should be between 0.99 and 1 in order to enable a slow convergence of the long-run component to $\omega$. The CGARCH can capture asymmetric effect into the transitory component, such that:

$$
\begin{gathered}
m_{t}=\omega+\rho\left(m_{t-1}-\omega\right)+\phi\left(\varepsilon_{t-1}^{2}-h_{t-1}^{2}\right)+\theta_{1} z_{1 t} \\
h_{t}^{2}-m_{t}=\alpha\left(\varepsilon_{t-1}^{2}-m_{t-1}\right)+\pi\left(\varepsilon_{t-1}^{2}-m_{t-1}\right) d_{t-1} \\
+\beta\left(h_{t-1}^{2}-m_{t-1}\right)+\theta_{2} z_{2 t}
\end{gathered}
$$

where $z$ are exogenous variables, whole $d$ is the dummy variable for negative shocks, such that, transitory leverage effect will be present in the conditional variance if $\pi>0$. Recent application of the CGARCH model in modeling stock market volatility include Adrian and Rosenberg (2005) and Guo and Neely (2008), among others.

To measure risk premium, we introduce conditional variances in the mean equation for each of the models described above. This application is suitable for stock markets because the expected returns should be related to the expected risk. Generally, the model augments the variance in the mean equation, such that the mean equation (1) becomes:

$$
R_{t}=\mu+\lambda h_{t}^{2}+\varepsilon_{t} ; \varepsilon_{t} / \Omega_{t-1} \simeq N\left(0, h_{t}\right)
$$

where $\lambda$ denotes estimation coefficient reflecting a risk premium with respect to the conditional variance of stock prices; that is, it measures risk-return trade-off. A positive (and statistically significant) coefficient $\lambda$ implies that returns carry a risk premium, and vice versa. In the context of stock markets, until recently a number of studies have applied different versions of GARCH-M models [e.g., Abdalla (2012) and Guo and Neely (2008)].

\section{DATA AND PRELIMINARY TESTS}

We use daily observations of the COLCAP index, which includes most of the actively trading stocks. Data were obtained from the Colombian Stock Exchange spanning from January 17, 2008 to May 30, 2019, covering 2,770 observations of trading days. The index, which was quoted in Colombian pesos, was transformed into natural logs, in which the first log difference implies market returns.

In order to determine the pre- and post-MMF subsamples, we test if the MMF program created a regime shift. Therefore, we apply the Bai-Perron (2003) approach for multiple breakpoints. Based on F-statistics of 3.01, the following five breakpoints were detected at $5 \%$ significance level (critical value $=5.85)$ : November 9, 2010; July 18, 2012; March 31, 2014; December 15, 2015; and August 31,2017 . We pay attention to March 31, 2014, the date coinciding the commencement of implementing the External Resolution 025 of 2013 at the Colombian Stock Exchange. We use this date to split our data sample into two: sample 1 (the pre-MMF period, ending March 31, 2014) and sample 2 (the post-MMF period, from April 1, 2014 onwards). 
Table 1

Descriptive statistics and normality

\begin{tabular}{cccccccc}
\hline \multirow{3}{*}{ Log level } & Observations & Mean & $\begin{array}{c}\text { Standard } \\
\text { deviation }\end{array}$ & Skewness & Kurtosis & Jarque-Bera \\
\cline { 2 - 8 } & Whole & 2,770 & 7.26 & 0.21 & -1.12 & 3.64 & $621.79(0.00)$ \\
\cline { 2 - 8 } & Sample 1 & 1,496 & 7.25 & 0.26 & -0.92 & 2.37 & $236.49(0.00)$ \\
\cline { 2 - 8 } & Sample 2 & 1,274 & 7.26 & 0.10 & -0.17 & 2.85 & $7.41(0.03)$ \\
\hline \multirow{3}{*}{$\Delta \log$} & Whole & 2,769 & 0.00 & 0.01 & -0.37 & 11.15 & $7,719.39(0.00)$ \\
\cline { 2 - 8 } & Sample 1 & 1,495 & 0.00 & 0.01 & -0.45 & $4,565.24(0.00)$ \\
\cline { 2 - 8 } & Sample 2 & 1,274 & -0.00 & 0.01 & -0.17 & 5.74 & $405.56(0.00)$ \\
\hline
\end{tabular}

Source: Elaborated by the authors.

Table 1 presents descriptive statistics of the index in natural logs. From the Jarque-Bera test, there is a very strong evidence of non-normality in the index series, which is common for stock markets. The means and SD in both sample 1 and sample 2 are almost the same, suggesting little or no impact of the MMF on portfolio returns and volatility. Figure 1 depicts the series structure of the index (log levels) and returns (log differences). The presence of return clusters justifies the use of dependent variance volatility modeling. Figure 2 provides a better view of distribution in the index and returns, using quantiles of normal. Clearly, the quantiles of normal

$$
\text { Log levels }
$$

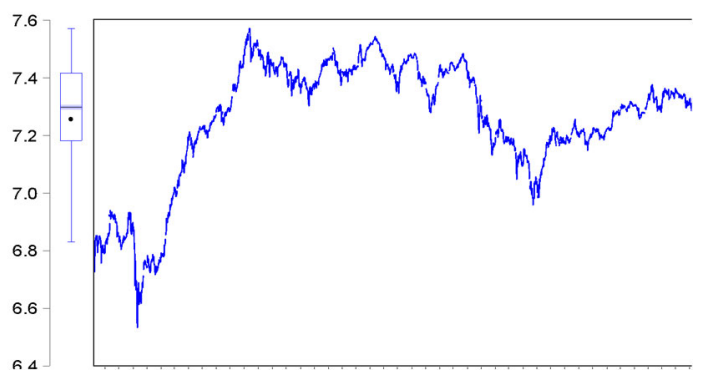

do not lie in the diagonal straight lines, suggesting that mainly positive shocks drive the index from normality, while both positive and negative shocks equally drive the returns from normality.

GARCH models require stationarity in time series. Therefore, unit root is tested using augmented Dickey Fuller (ADF) and Phillip-Perron (PP). Detailed discussion about the applications of these tests is found in Wang (2003) and Dionisio et al. (2007). The test results suggested that the index levels are non-stationary while the returns are stationary. Therefore, the data is suitable for GARCH modeling with returns.

\section{Returns}

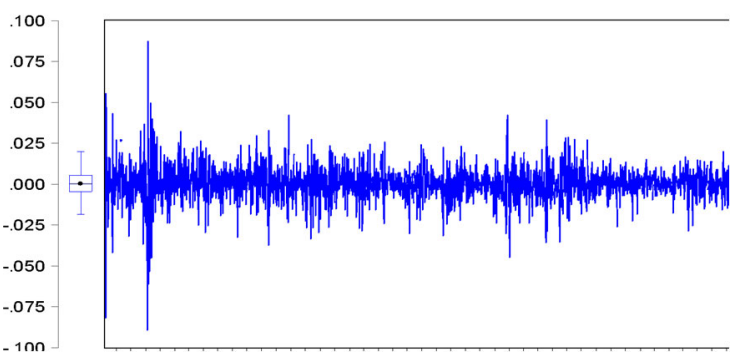

Figure 1 Structure of Colombian stock prices and returns (December 1, 2006 to June 13, 2011)

Source: Elaborated by the authors.

Log levels

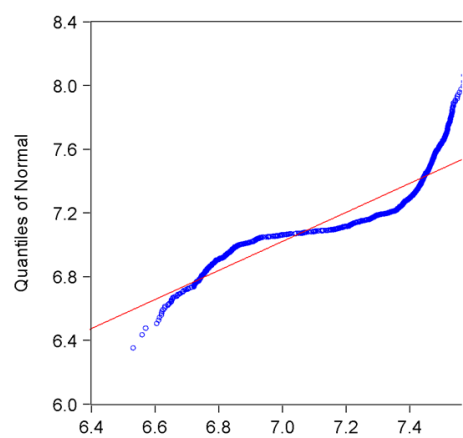

Returns

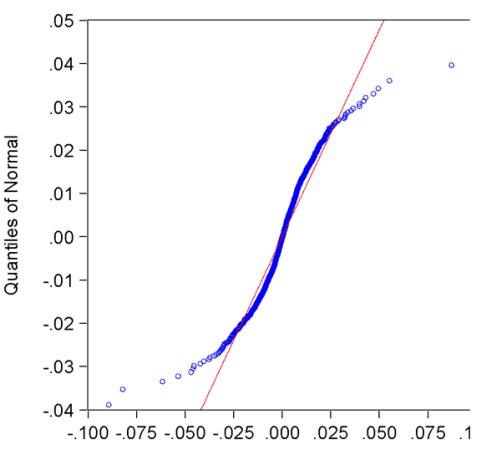

Figure 2 Quantiles of normal

Source: Elaborated by the authors. 


\section{EMPIRICAL ESTIMATION AND RESULTS}

\subsection{Model Specifications}

In our GARCH models, mean equations were estimated without the constant (preliminary tests suggested 0 values in the constant coefficient, and was mostly statistically insignificant). However, all mean equations include exogenous variables for different purposes. First, autoregressive stock returns (from lag 1 to 4) were included in order examine the effect of previous returns on current returns; that is, if current returns can be used to predict future returns in (from day 1 to day 4). Second, the MMF dummy was introduced in mean equations (for the whole series) in order to examine the impact of MMF on stock returns; the dummy carries a value of 0 pre 1 April, 2014 and 1 afterwards. Third, in order to measure risk premium, conditional SD were included in mean equations. Therefore, our GARCH process is referred to as GARCH-in-mean: GARCH-M, TARCH-M, EGARCH-M, and CGARCH-M.

Variance equations were estimated with orders: $p=1$ and $q=1$. Initially, all models were estimated with three types of error distribution assumptions: normal (Gaussian) distribution, Student's $t$ distribution, and the generalized error distribution (GED), which were estimated by the method of maximum likelihood. Then, different information criteria [log-likelihood information criteria (LL), Akaike's information criteria (AIC), Schwartz information criteria (SIC), and Hannan-Quinn information criteria (HQIS)] were used to determine the most suitable distribution. Although the estimated results were consistent for all distributions assumptions, the GED distribution appeared to be the best fit, from which we report our results here.

\subsection{Empirical Results}

Results for mean and variance equations were summarized and are reported in Table 2. Diagnostic tests were performed based on Lagrange multiplier (LM) tests for ARCH in the residuals. A model is regarded as efficient if no traces of ARCH remained, but ARCH itself does not invalidate inference on estimates (Engle, 1982). In most of our models, there were indications of little ARCH effects, hence they are considered reasonably efficient. Based on diagnostic tests and information criteria rankings (LL, AIC, SIC, and HQIS), the EGARCH-M model seems to outsmart other models, ahead of the TARCH-M and CGARCH. The standard GARCH-M model is ranked last. Despite these rankings, the estimated coefficients are consistent in most cases. In few cases, however, where estimates are contradicting, our inferences are made by giving more weight on the EGARCH-M.

Table 2

Findings for volatility, risk premium, and information asymmetry

\begin{tabular}{|c|c|c|c|c|c|}
\hline Aspect & Model & Whole & Sample 1 & Sample 2 & Remarks \\
\hline \multicolumn{6}{|l|}{ Mean equation } \\
\hline \multirow{4}{*}{$\begin{array}{l}\text { Coefficients for the effect of previous } \\
\text { information on returns (lag } 1 \text { ) }\end{array}$} & GARCH-M & 0.09 & 0.05 & 0.15 & Increase \\
\hline & TARCH-M & 0.10 & 0.06 & 0.15 & Increase \\
\hline & EGARCH-M & 0.10 & 0.06 & 0.16 & Increase \\
\hline & CGARCH-M & 0.09 & 0.06 & 0.15 & Increase \\
\hline \multicolumn{6}{|l|}{ Mean equation } \\
\hline \multirow{4}{*}{$\begin{array}{l}\text { Coefficients for the effect of previous } \\
\text { information on returns (lag } 4)\end{array}$} & GARCH-M & -0.04 & -0.05 & -0.01 & Increase \\
\hline & TARCH-M & -0.03 & -0.05 & $-0.01 *$ & Possible increase \\
\hline & EGARCH-M & -0.03 & $-0.04 *$ & $-0.02 *$ & Possible increase \\
\hline & CGARCH-M & $-0.03^{*}$ & -0.06 & $-0.02 *$ & Possible increase \\
\hline \multicolumn{6}{|l|}{ Mean equation } \\
\hline \multirow{4}{*}{$\begin{array}{l}\text { Coefficients for magnitude of portfolio } \\
\text { returns (dummy variable) }\end{array}$} & GARCH-M, Dummy & $-0.00^{*}$ & & & Possible decline \\
\hline & TARCH-M, Dummy & -0.00 & & & Decline \\
\hline & EGARCH-M, Dummy & -0.00 & & & Decline \\
\hline & CGARCH-M, Dummy & -0.00 & & & Decline \\
\hline
\end{tabular}


Table 2

Cont.

\begin{tabular}{|c|c|c|c|c|c|}
\hline Aspect & Model & Whole & Sample 1 & Sample 2 & Remarks \\
\hline \multicolumn{6}{|l|}{ Mean equation } \\
\hline \multirow{4}{*}{ Coefficients for risk premium } & GARCH-M & 0.08 & 0.08 & $0.02 *$ & Possible decline \\
\hline & TARCH-M & 0.06 & 0.06 & $0.00^{*}$ & Possible decline \\
\hline & EGARCH-M & 0.06 & 0.05 & $-0.00^{*}$ & Possible decline \\
\hline & CGARCH-M & 0.07 & 0.09 & $0.02 *$ & Possible decline \\
\hline \multicolumn{6}{|l|}{ Variance equation } \\
\hline \multirow{3}{*}{ Coefficients for volatility persistence } & GARCH-M & 0.95 & 0.94 & 0.94 & No impact \\
\hline & TARCH-M & 0.89 & 0.84 & 0.87 & Slight increase \\
\hline & EGARCH-M & 0.94 & 0.92 & 0.93 & Slight increase \\
\hline Short-run persistence & CGARCH-M & 0.70 & $0.54^{*}$ & $0.84^{*}$ & Possible increase \\
\hline Long-run persistence & CGARCH-M & 1.04 & 1.04 & 1.02 & Decline \\
\hline \multicolumn{6}{|l|}{ Variance equation } \\
\hline \multirow{3}{*}{ Coefficients for information asymmetry } & TARCH-M & 0.11 & 0.13 & 0.13 & No impact \\
\hline & EGARCH-M & -0.08 & -0.09 & -0.09 & No impact \\
\hline & CGARCH-M & 0.11 & 0.19 & $0.00^{*}$ & Possible decline \\
\hline \multicolumn{6}{|l|}{ Descriptive statistics } \\
\hline \multirow{4}{*}{ Standard deviation of dependence variance } & GARCH-M & 0.01 & 0.01 & 0.01 & No impact \\
\hline & TARCH-M & 0.01 & 0.01 & 0.01 & No impact \\
\hline & EGARCH-M & 0.01 & 0.01 & 0.01 & No impact \\
\hline & CGARCH-M & 0.01 & 0.01 & 0.01 & No impact \\
\hline
\end{tabular}

Note: This table presents a summary of all key findings for volatility modeling. Remarks are based on overall inference from estimates of each model.

${ }^{*}=$ coefficients whose estimates are not statistically significant, in which inference is made but without drawing absolute conclusions.

Source: Elaborated by the authors.

Regarding mean equations, estimated coefficients for lagged market returns were statistically insignificant for lag 2 and lag 4, but statistically significant for lag 1 and lag 4. In Table 2, mean equations on lagged market returns, all coefficients on lag 1 are positive. This suggests that previous returns are associated with an increase in current returns and last only for one trading day - current returns can predict an increase in next day's returns. The magnitude of these effects increased following the MMF program, from approximately 5-6\% to $15-$ $16 \%$. In contrast, all coefficients on lag 4 are negative, but statistically significant only for GARCH-M and TARCH-M (whole and sample 1) and CGARCH (sample 1). Although these results are weak, they signify that current market returns can be used to predict decline in returns in the next four days. The dummy variable for MMF $\left(\mathrm{SD}_{2014}\right)$ is lowly negative (approaching 0 ) and statistically significant, except for the GARCH-M process. Hence, while investors receive very small returns overall, there is evidence to suggest a slight decline in those returns following the MMF program. This corroborates descriptive statistics in Table 1, where average returns are negative in sample 2 .

Regarding risk premium, estimates for all models are consistent. The coefficient $(\lambda)$ is positive and statistically significant for whole and sample 1 only, implying consistency with finance theory. In contrast, it is statistically insignificant for sample 2 in all models, and it is negative on the CGARCH-M. Based on whole series and sample 1, the overall risk compensation is approximately between 5 and $9 \%$. We can not make inference on sample 2 (post-MMF) because estimates are statistically insignificant, but they may imply a reduction in risk compensation following MMF reforms, to perhaps none.

In variance equations, estimated coefficients for both news shocks and variance shocks are statistically significant, except news shocks on the CGARCH model (whole and sample 1). All models are consistent in that the coefficients for variance shocks are greater than those 
of news shocks, suggesting that the persistence in variance tends to have more influence on conditional volatility than news shocks. Estimated values for volatility persistence are relatively high, but not permanent. The MMF reforms seem to be associated with no change or merely a slight increase in volatility persistence (including short-run persistence). Long-term persistence, however, seems to have decreased slightly from 1.04 to 1.02 . The coefficients for information asymmetry were statistically significant at $1 \%$ level. As expected, the coefficient is negative on the EGARCH and positive on the TARCH and CGARCH, except on sample 2 of the CGARCH model (which is statistically insignificant). Overall, bad news tends to accelerate more volatility than good news.

\section{DISCUSSION AND POLICY IMPLICATIONS}

This study aims at examining the impact of reforms in the Colombian stock market, following MILA integrations and the introduction of the MMF. The main focus was on how MMF affected stock market volatility in respect of three volatility-related responses: persistence, risk premium, and information asymmetry. These three responses are discussed in relation to the main objectives of MMF, a key reform feature in the MILA framework - to create market efficiency through improving active stock trading, aided by effective communication in the brokerage system.

\subsection{Risk Premium}

$\mathrm{H}_{1}$ refers to risk premium. It is posited that stock returns should carry a risk premium as a compensation for risk (volatility). From our key findings, stock returns in the Colombian market seem to be consistent with the finance theory on risk compensation - the higher the risk the higher the return. However, there are indications that investors receive less risk compensation following the MMF reforms. Hence, results do not support $\mathrm{H}_{1}$.

This impact on risk premium can have several implications. According to Fattoum et al. (2014), risk premium in emerging stock markets is a function of domestic factors, global factors, and exchange rate risk. In Colombia, the fact that the implementation of MMF is associated with a reduction in risk premium (or none) can be explained by evidence of a slight decline in returns after the MMF, as indicated by negative coefficients of the MMF dummy variable (Table 2) and negative returns in descriptive statistics (Table 1). At the same time, while returns seem to have declined, the SD of conditional volatility has remained unchanged at 0.01 in both preand post-MMF periods (Table 2), consistent with static SD (Table 1).

If the MMF reforms, and MILA as a whole, are effective, stock market volatility should increase because investors should be more exposed to different types of risk due to market expansion beyond domestic borders. Hence, a decline in risk compensation can be a disincentive for investors, who may opt for other alternative markets or investment opportunities where risk is better compensated. Perhaps this can be one of the factors for a slow development of the Colombian stock market, as measured by its deteriorating share of GDP in terms of size, trading volume, and free float [see Arbeláez (2009) and Wyman (2016)]. Indeed, the drop of annual growth of trading volume from $33.9 \%$ in 2016 to $-4.5 \%$ in 2018 is alarming.

\subsection{Volatility Persistence}

Results in Table 2 show high volatility persistence as expected, hence supporting $\mathrm{H}_{2}$. MMF reforms seem to have little or no impact on volatility persistence. From Figure 1, clearly stock prices declined during the early stages of MMF reforms, alongside a change in volatility clustering in return (to higher swings). This provides evidence that the market was initially very reactively sensitive to the MMF. This can be described as chaotic market reactions according to Beran (1994) and Campbell et al. (1997). These results are consistent with the literature (Andersen et al. 2003; Dutta et al. 2017). Nevertheless, the disappearance of these large return swings afterwards implies that the market chaotic reaction did not last long. The fact that volatility persistence is relatively high suggests that investors should implement risk management strategies to match their long-term investment portfolios, without worrying about MMF reform measures.

\subsection{Information Asymmetry}

Regarding information asymmetry, as expected, our results suggest that the market tends to react more to bad news than good news, and is consistent with theory and earlier empirical evidence on stock markets [e.g., Bekaert and Wu (2000), Black (1976), Brandt and Kang (2004), Brown et al. (1988), Campbell (1992), Engle and $\mathrm{Ng}$ (1993), French et al. (1987), and Nelson (1991)] 
followed by a series of other studies [e.g., Girard and Biswas (2007), Shin (2005), and Todea (2016)]. Clearly, the MMF program seems to have not changed the information asymmetry in the Colombian stock market. Hence, results do not support $\mathrm{H}_{3}$.

This may have several implications. In particular, there is a possibility that the Colombian stock market has not changed structurally in terms of factors that tend to lower information asymmetry (such as more influence of institutional investors and more liquidity) and factors that tend to amplify information asymmetry (such as more influence of individual investors, fast equity transfers, and more insider activities [see Chung and Wang (2016), Duarte and Young (2009), among others].

If we relate the results on information asymmetry and volatility persistence to the objectives of MMF (i.e., to create market efficiency by structuring and implementation of a stockbroker's commitment to stock trading), and considering the findings in Yepes-Rios et al. (2015) (i.e., MILA initiatives have resulted in changes in ownership and internationalization of the brokerage firms), there should be implied improvements in integration between the Colombian stock market and other markets. This is because improving the roles of market-makers should be reflected in quicker information flow and responses among market participants in the domestic and foreign markets. The fact that the MMF has not altered market responses on the magnitude information asymmetry (and perhaps no impact on volatility persistence) implies a continuing stagnant or inactive market. This also implies that the MMF might have not improved the role of stockbrokers as expected regarding the speed of information sharing, trading activities, and stock transfers.

\subsection{Policy Implications}

Based on our results about volatility, the MMF program (within MILA reforms) does not seem to have improved market efficiency of the Colombian stock market, which was its main objective. This poses challenges to policy makers and regulators, calling for the need to find answers on this issue. This paper does not provide answers to this question.

Instead, we propose the need to investigate the factors hindering market efficiency in Colombia even after MMF reforms. Evidence from previous studies provide a list of those factors, such as transaction costs, liquidity, speed and frequency of trading activities, the institutional structure, alternative trading venues, and alternative investment opportunities [see, for example, Brogaard et al. (2012), Hasbrouck (1995), and O'Hara (2003)]. Moreover, policy makers and regulators may consider what measures to be taken in order to overcome the existing limiting factors, including a more effective way of addressing recommendation issues during the WEF in 2016. Is it possible that the structure and mechanism of the MMF may not be suitable for the Colombian market, and that it requires restructuring?

\section{CONCLUSION AND FURTHER RESEARCH}

This study shows that, overall, the MMF is associated with an increase in the magnitude in which last day's returns can predict current returns, although overall average returns seem to have declined after the MMF. Regarding risk premium, the results suggest the existence of a positive risk-return tradeoff throughout the period under investigation. However, there is no strong evidence to make conclusions about the MMF impact on risk compensation despite signs on a decline. Likewise, information asymmetry exists in the Colombian stock market, but the MMF does not appear to have altered its magnitude. Volatility persistence seems to be relatively high overall, with an indication of a slight increase following the MMF initiative. These findings suggest adoption of MMF in Colombia has not affected the way the market behaves in terms of volatility. Overall, this implies lack of improvement and hence the effectiveness of the reform.

For further research, it may also be valuable to investigate the impact of MMF on market integration among the four member countries (Colombia, Chile, Peru, and Mexico), together with a comparative study on the extent at which MMF in each individual country has impacted volatility and market efficiency. Knowledge on these aspects will illuminate light to market regulators towards further improvements, if necessary. 


\section{REFERENCES}

Abdalla, S. (2012). The risk-return trade-off in emerging stock markets: Evidence from Saudi Arabia and Egypt. International Journal of Economics and Finance, 4(6), 11-21.

Adrian, T., \& Rosenberg, J. (2005). Stock returns and volatility: Pricing the long-run and short-run components of market risk [Working Paper]. Federal Reserve Bank of New York.

Agudelo, D., Villaraga, E., \& Giraldo, S. (2011). Does information asymmetry matter in emerging markets? Evidence from six Latin American stock markets [Working Paper]. IDEAS.

Andersen, T. G., Bollerslev, T., Diebold, F. X., Labys, P. (2003). Modeling and forecasting realized volatility. Econometrica, 71(2), 579-625.

Bai, J. \& Perron, P. (2003), Critical values for multiple structural change tests. Econometrics Journal, 6(1), 72-78.

Bekaert, G., \& Wu, G. (2000). Asymmetric volatility and risk in equity markets. The Review of Financial Studies, 13(1), 1-42.

Beran, J. (1994). Statistics for long-memory process. Chapman and Hall/CRC.

Berggrun, L., Cardona, E., \& Lizarzaburu, E. (2020). Firm profitability and expected stock returns: Evidence from Latin America. Research in International Business and Finance, 51(C).

Berggrun, L., Lizarzaburu, E., \& Cardona, E. (2016). Idiosyncratic volatility and stock returns: Evidence for the MILA. Research in International Business, 37(C), 422-434.

Black, F. (1976). Studies in stock price volatility changes. The 1976 Business Meeting of the Business and Economic Statistics Section. American Statistical Association.

Bolañosa, E. R. L., Burneob, K., Galindoc, H., \& Berggrun, L. (2015). Emerging markets integration in Latin America (MILA) stock market indicators: Chile, Colombia, and Peru. Journal of Economics, Finance and Administrative Science, 20(39), 74-83.

Bollerslev, T. (1986). Generalized autoregressive conditional heteroskedasticity. Journal of Econometrics, 31(3), 307-327.

Bollerslev, T., \& Jubinski, D. (1999). Equity trading volume and volatility: Latent information arrivals and common long-run dependencies. Journal of Business and Economics Statistics, 17(1), 9-21.

Brandt, M. W., \& Kang, Q. (2004). On the relationship between the conditional mean and volatility on stock returns: A latent VAR approach. Journal of Financial Economics, 72(2), 217257.

Brogaard, J., Hendershott, T., \& Riordan, R. (2012). High frequency trading and price discovery. Social Science Research Network. http://ssrn.com/abstract=1928510

Brown, K., Harlow, W. V., \& Tinic, S. M. (1988). Risk aversion, uncertain information, and market efficiency. Journal of Financial Economics, 22(2), 355-385.

Campbell, J. Y. (1992). No news is good news. Journal of Financial Economics, 31(3), 281-318.

Campbell, J. Y., Lo, A. W., \& MacKinlay, A. C. (1997). The econometrics of financial markets. Princeton University Press.
Charles, A., \& Darné, O. (2009). Variance-ratio tests of random walk: An overview. Journal of Economic Surveys, 23(3), 503527.

Choi, J. J., Lam, K. C., Sami, H., \& Zhou, H. (2013). Foreign ownership and information asymmetry. Asia-Pacific Journal of Financial Studies, 42(2), 141-166.

Choi, N. Y., \& Sias, R. W. (2012). Why does financial strength forecast stock returns? Evidence from subsequent demand by institutional investors. Review of Financial Studies, 25(5), 1550-1587.

Chuang, H. (2015). Volatility persistence in stock markets. Economic Letters, 113(1), 64-67.

Chung, C., \& Wang, K. (2016). The impact of individual investor trading on information asymmetry in the Korean stock market. North American Journal of Economics and Finance, 37(C), 472-484.

Dionisio, A., Menezes, R., \& Mendes, D. A. (2007). On the integrated behaviour of non-stationary volatility in stock markets. Physica, 382(1), 58-65.

Dorodnykh, E. (2014). Stock market integration: An international perspective. Palgrave MacMillan.

Duarte, J., \& Young, L. (2009). Why is PIN priced? Journal of Financial Economics, 91(2), 119-138.

Dutta, S., Essaddam, N., Kumar, V., \& Saadi, S. (2017). How does electronic trading affect efficiency of stock market and conditional volatility? Evidence from Toronto Stock Exchange. Research in International Business and Finance, 39(B), 867-877.

Engle, R., \& Lee, G. (1999). A long-run and short-run component model of stock return volatility. In R. Engle, \& H. White (Eds.), Cointegration, causality and forecasting. Oxford University Press.

Engle, R. F., \& Ng, V. K. (1993). Measuring and testing the impact of news on volatility. Journal of Finance, 48(5), 17491778.

Engle, R. F. (1982). Autoregressive conditional heteroscedasticity with estimates of the variance of UK inflation. Econometrica, 50(4) 987-1008.

Espinosa-Mendez, C., Gorigoitía, J., \& Vieito, J. (2017). Is the virtual integration of financial markets beneficial in emerging markets? Evidence from MILA. Emerging Markets Finance and Trade, 53(10), 2279-2302.

Fattoum, S., Guesmi, K., \& Moschetto, B. (2014). The evolution of risk premiums in emerging stock markets: The case of Latin America and Asia region. Journal of Applied Business Research, 30(2) 353-360.

French, K. R., Schwert, G. W., \& Stambaugh, R. F. (1987). Expected stock returns and volatility. Journal of Financial Economics, 19(1), 3-29.

García, F., González-Bueno, J. A., \& Oliver, J. (2015). Meanvariance investment strategy applied in emerging financial markets: Evidence from the Colombian stock market. Intellectual Economics, 9(1)22-29. 
Girard, E., \& Biswas, R. (2007). Trading volume and market volatility: Developed versus emerging stock markets. The Financial Review, 42(3), 429-459.

Glosten, L. R., Jaganathan, R., \& Runkle, D. (1993). On the relation between the expected value and the volatility of the normal excess return on stocks. Journal of Finance, 48(5), 1779-1801.

Guo, H., \& Neely, C. J. (2008). Investigating the intertemporal risk-return relation in international stock markets with the component GARCH model. Economics Letters, 99(2), 371374.

Hardy, N., Magner, N. S., Lavin, J., Cardenas, R. A., \& JaraBertin, M. (2018). Small consequences of a major agreement: The MILA case. Academia Revista Latinoamerica de Administracion, 31(4) 486-518.

Harris, L. (2003). Trading \& exchanges - Market microstructure for practitioners. Oxford University Press.

Harrison, B., \& Moore, W. (2012). Stock market efficiency, non-linearity, thin trading and asymmetric information in MENA stock markets. Economic Issues, 17(1), 77-93.

Hasbrouck, J. (1995). One security, many markets: Determining the contributions to price discovery. The Journal of Finance, 50(4), 1175-1199.

Hasbrouck, J. (2007). Empirical market microstructure: The institutions, economics, and econometrics of securities trading. Oxford University Press.

Hasbrouck, J. (2009). Trading costs and returns for U.S. equities: Estimating effective costs from daily data. Journal of Finance, 64(3), 1445-1477.

Kumar, R. (2018). Risk, uncertainty and stock returns predictability - A case of emerging equity markets. Journal of Financial Economic Policy, 10(4), 438-455.

Lee, C. F., Chen, G. M., \& Rui, O. M. (2001). Stock returns and volatility on China's stock markets. Journal of Finance Research, 24(4), 523-544.

Leraul, D. J. (2016). Trading with neighbors: Regional Stock Exchange integration - The Mercado Integrado Latinoamericano. Latin American Business Review, 17(1), 49-71.

Lintner, J. (1965), The valuation of risk assets and the selection of risky investments in stock portfolios and capital budgets. The Review of Economics and Statistics, 47(1), 13-37.

Lizarzaburu, E. R., Burneo, K., Galindo, H., \& Berggrun, L. (2015). Emerging markets integration in Latin America (MILA) stock market indicators: Chile, Colombia, and Peru (2008-2013). Journal of Economics, Finance and Administrative Science, 20(39) 74-83.

Markowitz, H. (1959). Portfolio selection: Efficient diversification and investments. John Wiley and Sons.

Martins, O., \& Paulo, E. (2014). Information asymmetry in stock trading, economic and financial characteristics and corporate governance in the Brazilian stock market. Revista Contabilidade \& Finanças, 25(64), 33-45.

Mellado, C., \& Escobari, D. (2015). Virtual integration of financial markets: A dynamic correlation analysis of the creation of the
Latin American integrated market. Applied Economics, 47(19), 1956-1971.

Mukherjee, K., \& Mishra, R. K. (2010). Stock market integration and volatility spillover: India and its major Asian counterparts. Research in International Business and Finance, 24(2), 235-251.

Nelson, D. B. (1991). Conditional heteroskedasticity in asset returns: A new approach. Econometrica, 59(2), 347-370.

O'Hara, M. (2003). Liquidity and price discovery. The Journal of Finance, 58(4), 1335-1354.

Poon, S. H., \& Granger, C. (2003). Forecasting financial market volatility: A review. Journal of Economic Literature, 41(2), 478-539.

Rojas-Mora, J., \& Chamorro-Futinico, J. C. (2017). Dynamics and volatility at stock market indexes of pacific alliance countries. Panorama Económico, 24(1), 71-84.

Sandoval-Alamos, E., Vásquez-Parraga, A. Z., \& Sabat Arriagada, R. (2015). Integración de los mercados accionarios de Chile, Colombia y Perú en el Mercado Integrado Latinoamericano (MILA). Innovar, 25, 71-84.

Santillán-Salgado, R. J., Roldán, M., \& Miranda, M. R. (2017). An exploratory study on nonlinear causality among the MILA markets. Emerging Markets Finance and Trade, 53(10), 23032317.

Sanyal, P., Gahan, P., Sanyal, P., \& Gahan, P. (2016). Volatility behaviour in emerging stock markets A GARCH approach. International Journal of Business Analytics and Intelligence, 4(2), 21-35.

Sehgal, S., \& Garg, V. (2016). Cross-sectional volatility and stock returns: Evidence for emerging markets. Vikalpa: The Journal for Decision Makers, 41(3), 1-13.

Sharma, P., \& Vipul, P. (2016). Forecasting stock market volatility using realized GARCH model: International evidence. Quarterly Review of Economics and Finance, 59(C), 222-230.

Sharpe, W. F. (1964). Capital asset prices: A theory of market equilibrium under conditions of risk. The Journal of Finance, 19(3), 425-442.

Shin, J. (2005). Stock returns and volatility in emerging stock markets. International Journal of Business and Economics, 4(1), 31-43.

Siqueira, L., Amaral, H., \& Correia, L. (2017). The effect of asymmetric information risk on returns of stocks traded on the BM\&FBOVESPA, Revista Contabilidade \& Finanças, 28(75), 425-444.

Srinivasan, P. (2011). Modeling and forecasting the stock market volatility of S\&P 500 index using GARCH models. IUP Journal of Behavioral Finance, 8(1), 51-69.

Todea, A. (2016). Cross-correlations between volatility, volatility persistence and stock market integration: The case of emergent stock markets, Chaos, Solitons and Fractals, 87, 208-215.

Tripathy, T., \& Gil-Alana, L. A. (2010). Suitability of volatility models for forecasting stock market returns: A study on the Indian National Stock Exchange. American Journal of Applied Science, 7(11), 1487-1494. 
Tripathy, T., \& Gil-Alana, L. A. (2015). Modelling time-varying volatility in the Indian stock returns: Some empirical evidence. Review of Development Finance, 5(2), 91-97.

Wang, P. (2003). Financial econometrics: Methods and models. Routledge.

Wyman, O. (2016). Accelerating capital markets development in emerging economies country case studies. The World Economic Forum.

Yang, J. (2003). Market segmentation and information asymmetry in Chinese stock markets: A VAR analysis. Financial Review, 38(4), 591-609.

Yepes-Rios, B., Gonzalez-Tapia, K., \& Gonzalez-Perez, M. A. (2015). The integration of stock exchanges: The case of the
Latin American Integrated Market (MILA) and its impact on ownership and internationalization status in Colombian brokerage firms. Journal of Economics, Finance and Administrative Science, 20(39), 84-93.

Zakoïan, J. M. (1994). Threshold heteroskedastic models. Journal of Economic Dynamics and Control, 18(5), 931-944.

Zhang J., Liu Y. (2010). The interaction between market size and volatility of stock price: An empirical study. Management Review, 22(10), 22-28.

Zhou, Q., \& Zhou, Z. (2005). Stock returns, volatility, and cointegration among Chinese stock markets. China World Economy, 13(2), 106-122. 